\title{
En busca de las causas del crimen Teorías y estudios sobre delincuencia y justicia penal en la España Moderna
}

\author{
Ángel Alloza Aparicio *
}

\section{RESUMEN ABSTRACT}

A partir de una sintesis de las teorías criminológicas más relevantes de los últimos tiempos, una incursión en el pensamiento de los doctores españoles de los siglos xVI y xvII sobre

la voluntad del ser humano, $y$ un corpus historiográfico sobre el crimen y la justicia penal en la España moderna, este articulo explora las causas que más comúnmente han provocado los distintos tipos de delincuencia, y cómo éstas son percibidas por historiadores, sociólogos y criminólogos.
On the basis of a survey of relevant criminological theories, an incursion into the sixteenth and seventeenth century Spanish Doctors thought, and a corpus of historiography on crime and criminal justice in Early Modern Spain, this article explores the causes that most commonly provoked the different types of criminality, and how these causes have been perceived by scholars.

La delincuencia ha constituido siempre un problema que ha preocupado enormemente al conjunto de la sociedad, aunque en mayor medida ha inquietado a las víctimas de delitos y a aquellas otras personas encargadas de la seguridad y del mantenimiento de la paz. La inquietud provocada por la criminalidad en la época moderna se debía asimismo a la incomodidad e inseguridad que provocaba entre la población, pero

* UNED, Madrid. 
también al desafío que suponía al poder real, en una época en que éste trataba de consolidarse y extenderse. Los Reyes Católicos hicieron lo imposible por ampliar la legislación penal y crear instituciones represivas, como la Santa Hermandad y el Santo Oficio, a fin de proteger a la sociedad y a los oficiales reales encargados del mantenimiento del orden. Con aquella política perseguían el respeto y la obediencia a la autoridad soberana en todos sus reinos, porque debido a las reiteradas luchas antinobiliarias y guerras de carácter político, la delincuencia se había hecho endémica durante el reinado de Enrique IV 1.

No resulta extraño que desde antiguo se hayan querido conocer las causas de la delincuencia, su alcance numérico y la distinta naturaleza de los delitos, porque ello permitía combatirla con más eficacia. En las Relaciones Topográficas mandadas realizar en los pueblos castellanos por Felipe II se indaga ya sobre la delincuencia acaecida en ellos. La pregunta 37 del cuestionario de 1575 y la 32 del de 1578 preguntan a los naturales acerca de los robos y delitos famosos que se hubieran registrado recientemente en sus localidades.

Los inventarios de causas criminales que ordenaron elaborar los alcaldes de Corte hacia mediados del siglo XVIII registraron los casos delictivos acaecidos en Madrid y su rastro desde el último tercio del siglo XVI hasta fines de la centuria del Setecientos, y constituyen un espléndido ejemplo de ese interés por conocer el alcance real de ia actividad de los tribunales de justicia cortesanos. En Castilla, fue tal vez el reinado de Carlos III el primero que desarrolló una prematura sociología criminal, con la convicción de que para remediar los males de la sociedad había que averiguar antes el motivo que los causaba ${ }^{2}$. En este contexto hay que destacar los concursos fomentados por su gobierno premiando los mejores escritos sobre seguridad pública ${ }^{3}$.

En otros ámbitos europeos se desarrollaron también instrumentos para conocer mejor el problema de la delincuencia en la época moderna. Sir William Petty, padre de la aritmética política inglesa, afirma-

TOMÁS Y VALIENTE, F., El derecho penal de la Monarquía Absoluta (Siglos XVI-XVII-XVIII). Madrid, 1969, pp. 23-46

2 Un análisis del contenido de los referidos inventarios en ALLOZA, A., La vara quebrada de la Justicia. Un estudio histórico sobre la delincuencia madrileña entre los siglos xvi y xVIII. Madrid, 2000.

3 Martinez Ruiz, E., La seguridad pública en el Madrid de la llustración. Madrid, 1988. pp. 181 y ss. 
ba en 1670 que los totales anuales de penas corporales, asi como los de reos encerrados por delitos graves, debían ser inventariados para conocer la extensión del vicio y del pecado en la nación. Un siglo más tarde, Jeremy Bentham reivindicó medidas similares con el objeto de que el legislador conociera mejor la realidad criminal y pudiera trabajar con más éxito, pues según el diseñador del panóptico, las listas de condenados podían constituir un barómetro político que indicaría el nivel de «salud moral» de las ciudades, de la misma forma que los índices de mortalidad indicaban su "salud física" 4 .

Sin embargo, las nociones de lo que es o no es criminal varian en el tiempo, y este hecho, unido a la propia multiplicidad de los delitos, ha dificultado enormemente a los historiadores, sociólogos y criminólogos la elaboración de una teoría general del fenómeno criminal y de sus causas. Los delitos contra la moral, como ha señalado recientemente Pieter Spierenburg, cambian a medida que lo hacen las ideas sobre sexualidad, género o privacidad. Así, el amancebamiento o la homosexualidad, que antes se castigaban duramente, dejaron de ser delitos en la mayor parte de los países europeos a fines del siglo XIX. Tales cambios aumentan la complejidad del fenómeno criminal, pero al mismo tiempo evidencian que el crimen está indefectiblemente vinculado al estado, porque a través de la legislación penal y la actividad de los tribunales, el poder público define lo que está dentro o fuera de la ley. A partir de estas premisas los historiadores han observado acertadamente dos procesos históricos paralelos: el de formación del estado y el de criminalización ${ }^{5}$.

Las dificultades a que se enfrentan los especialistas para producir una explicación al fenómeno de la delincuencia, como la variedad en la especie criminal, los cambios que experimenta con el tiempo, y aun la propia indeterminación de ciertos actos y comportamientos que pueden resultar delitos según y cuando se interprete la ley ${ }^{6}$, han resultado ser

4 Gatrell, V., Lenman, B. y Parker, G. (eds.), Crime and the Law. The Social History of Crime in Western Europe since 1500. London, 1980, p. 3.

5 Spierendurg, P., "Crime", Enciclopedia of European Social History. From 1350 to 2000. New York, 2001. Vol. III, pp. 335-348. Gatrell, Lenman y Parker (eds.), Crime and the Law, p. 6.

6 Tanto en la literatura jurídica actual como en la histórica se pueden encontrar numerosos capítulos dedicados a la noción de delito. Una defínición rápida con la que todos los historiadores trabajan para evitar perderse en complejas conceptualizaciones, hace referencia a toda actividad ilegal susceptible de ser perseguida judicialmente y castigada su autoria. 
insuficientes para disuadirles en su búsqueda de explicaciones orientadas a su comprensión, al menos desde las dos últimas centurias? Desde entonces no han cesado los intentos de explicación de este fenómeno que ha venido preocupado seriamente a las clases medias y gobernantes de los últimos tiempos. No en vano, son varias las escuelas de pensamiento criminológico que han elaborado teorías sobre las causas de la delincuencia, y al margen de éstas, existen múltiples formas de explicación causal: desde las promovidas por los que creen que el crimen es algo constante y consustancial a la especie humana -cuyo origen se halla en el pecado original-, hasta las ideadas por los que únicamente contemplan causas de carácter socio-económico.

Al socaire de esta preocupación, la Escuela clásica, cuya paternidad se ha achacado a Beccaría, ha propuesto que todas las personas actúan de acuerdo con su libre voluntad, racionalmente ejercida, y asegura que la actividad ilegal está motivada por los mismos principios que la legal, buscando la satisfacción y eludiendo el sufrimiento. La única diferencia entre ambas es que la primera se efectúa rompiendo las reglas (la ley). Por lo general, los sistemas legales actuales están basados en estos principios de libre voluntad y responsabilidad individual, si bien reconocen la existencia de agravantes y atenuantes, en especial los que derivan de la edad y el estado de salud mental de los reos ${ }^{8}$.

La Escuela positivista de criminología fue iniciada en la segunda mitad del siglo XIX por Leon Radzinowicz, quien comenzó a basar sus estudios sobre las causas del crimen en análisis empíricos, por medio de los cuales pudo postular la existencia de factores sociales, personales y ambientales como determinantes del comportamiento criminal. Dentro de este esquema se encuentran distintas interpretaciones que se pueden agrupar en biológicas-biosociales, psicológicas y sociológicas. Las primeras, representadas por el conocido doctor Lombroso, vinieron a asegurar que el comportamiento criminal estaba causado por

La segunda parte del libro de F. Tomás y Valiente, El derecho penal de la Monarquía Absoluta, está prácticamente dedicada por entero a ella.

Esto no quiere decir que antes del siglo xvil nadie se preocupara de reflexionar sobre la delincuencia, antes al contrario: el siglo xVI fue protagonista de la publicación de numerosos libros que incluian estudios sobre las causas que más comúnmente conducían a los hombres a cometer delitos. De ellos vamos a dar cuenta enseguida.

8 Un estudio sintético sobre las líneas de pensamiento criminológico, en SHOEMAKER, D.J., Theories of Delinquency. An examination of explanations of delinquent behavior. $3 .^{\text {a }}$ ed. Oxford, 1996. Sobre la escuela clásica, en la misma obra, pp. 12-20. 
algún mecanismo interno a los individuos, cuyos somatotipos -forma y estructura del cuerpo de los seres humanos- estaban relacionados con el comportamiento y el carácter.

Los integrantes italianos de esta escuela positivista de criminología vieron en la constitución orgánica y psíquica del individuo la raíz del delito, y en el medio social la ocasión para cometerlo. Para Lombroso, Garofalo o Ferry, el delincuente fortuito no existía, sino que siempre - aseguraban- se podía encontrar en él un elemento congénito. Por el contrario, los franceses consideraron el medio social como el caldo de cultivo de la delincuencia. Por eso para los primeros la responsabilidad del delito se encontraba en el individuo, mientras que para los segundos se hallaba en la sociedad: el delincuente era una víctima del orden social, de la miseria en que vivía ${ }^{9}$.

Las teorías psicológicas apuntan que las diferencias individuales en inteligencia, personalidad y otros factores, no sólo dividen a los criminales de los individuos que actúan dentro de la ley, sino que directa o indirectamente constituyen la causa de sus delitos. Este último modo explicativo sugiere que las personas que rompen la ley son deficientes en sentimientos morales básicos, y que esta insuficiencia se hereda. Por añadidura, aseguran que la falta de inteligencia fomenta el crimen, pues ésta lleva a las personas a ser menos capaces de controlar sus emociones y deseos ${ }^{10}$.

Entre las diversas explicaciones de carácter sociológico que surgieron desde fines del siglo $\mathrm{xIx}$ hasta la mita del $\mathrm{xx}$, existe una que ha gozado de mayor aceptación entre los historiadores, acaso porque ha conseguido establecer correlaciones entre las condiciones socio-económicas de largo plazo y las pautas de criminalidad constatadas en las últimas centurias. Por medio del concepto anomia (desorientación, falta de normalidad) Emile Durkheim defendió que la delincuencia estaba originada por factores sociales, cuyo origen residía en el colapso de las instituciones y controles de la comunidad, especialmente en las etapas de urbanización, rápida industrialización e inmigración que se conocieron entre finales del siglo XVIII y comienzos del xx. En su estudio Suicide. A Study in Sociology, el autor subrayó que la falta de nor-

\footnotetext{
9 Shoemaker, D., Theories. pp. 12-20, y Trinidad, P., La defensa de la sociedad. Cárcel $y$ delincuencia en España (siglos Xvil-XiX). Madrid, 1991, pp. 248-282.

10 ShoEmaker, D., Theories. pp. 21-74.
} 
malidad en esos periodos era el resultado del fracaso en la regulación de las expectativas «ilimitadas» de los individuos.

A partir de esta idea, algunos sociólogos americanos destacaron que el desfase entre las aspiraciones $u$ objetivos que las personas creen tener derecho a alcanzar y los medios legales u oportunidades para conseguirlos, constituye la principal fuente de delincuencia, pues los canales legítimos para lograr aquello que se desea no están al alcance de todọs, sino que vienen determinados por la distinta posición socio-económica de los individuos en la jerarquía social, a pesar de prevalecer en las sociedades actuales la ideología de igualdad de oportunidades. Entre los últimos hay que destacar las hipótesis de Merton, Cloward y Ohlin, según las cuales el bloqueo de las aspiraciones económicas causa pobreza de espíritu y un sentimiento general de frustración, lo que en muchos casos acaba conduciendo inexorablemente a la delincuencia ${ }^{11}$.

Cabe señalar finalmente la existencia de otras dos formas diametralmente opuestas de interpretar el comportamiento criminal: la Teoría del Control y la Teoría Radical de la delincuencia. Los representantes de la primera asumen que en la sociedad existe un consenso en torno a las normas y creencias morales convencionales, y que si hay crimen es porque ha fallado el sistema que lo reprime. De hecho, sus inspiradores mantienen que la sociedad debe estar controlada si se quiere erradicar el delito, dado que existen en ella múltiples presiones y circunstancias que inducen a delinquir, por eso sus representantes nunca se preguntan porqué se cometió un crimen, sino porqué no se cometió ${ }^{12}$.

Para los postulantes de la Teoría Radical, el comportamiento criminal es el resultado de los esfuerzos represivos de la clase dirigente para controlar a las masas, ya que no existe un consenso moral en la sociedad. Por esa razón, los efectos de la represión manifiestan no sólo ejemplos de delitos —generalmente de los sectores más bajos de

11 Shoemaker, D., Theories. pp. 75-133. Sobre el concepto Anomia y la correlación entre urbanización, industrialización, desorganización social y crimen, véase DURKHEIM, E., Suicide. A Study in Sociology. New York, 1951 )(original de 1897) y The Division of Labor in Society. London, 1933 (original de 1893). Basadas en estas premisas pero desarrollando aún más las ideas de la desigualdad de oportunidades y de los desajustes entre las aspiraciones legítimas y las capacidades reales, se encuentran las tesis de Clowaro, R., y OHLIN, L., Delinquency and Opportunity. A theory of Delinquent Gangs. New York, 1969; así como la de MERTON, R., Social Theory and Social Structure. New York, 1957.

12 ShOEMAKER, Theories, pp. 156-190. 
la sociedad-, sino también los objetivos de la clase dominante, especialmente cuando clasifican como crímenes las acciones de los trabajadores con el objeto de facilitar su control. Esta última forma explicativa deriva de una interpretación mucho más general de la delincuencia, basada en el conflicto social o lucha de clases ${ }^{13}$.

\section{ESPAÑA: SIGLOS XVI Y XVII}

Mejor desarrolladas que sus antecesoras, estas teorías contemporáneas han influido en mayor o menor medida en las políticas penales y de orden público desplegadas durante las últimas décadas en casi todos los países del mundo Occidental. Pero no son enteramente originales, porque sus ideas básicas ya se encontraban insertas en las obras de los doctores, teólogos moralistas y juristas españoles de los siglos XVI y XVII. Veamos entonces cómo percibían el crimen, desde el punto de vista de sus causas, los intelectuales de la época moderna en España.

Un punto de partida alentador para adentrarse en esta cuestión es que entonces, como ahora, se veía en el ser humano en lugar de procedencia de las malas acciones, de los delitos. En cambio, lo que nuestros intelectuales del siglo XVI discutieron, a diferencia de los actuales, es si el hombre realizaba los crímenes impulsado por fuerzas misteriosas e irresistibles, como pensaban algunos, o si por el contrario estaba en su poder el cometerlos o no cometerlos. Es decir, debatieron sobre la existencia o inexistencia de la libertad humana, del libre albedrío. La cuestión es de una relevancia notable, porque si se negaba la libertad humana y se pensaba que el hombre actuaba movido, como el mercado, por una mano invisible, carecía en consecuencia de responsabilidad alguna sobre sus actos y, por lo tanto, no se le podía culpar por la comisión de sus delitos. En cambio, si verdaderamente existía la libertad humana, el hombre era enteramente responsable de lo que hacía.

13 Sobre este modelo puede verse SUMmER, C., "Marxism and deviancy theory", en P. Wiles (ed.), The Sociology of Crime and Delinquency (The New Criminologies). New York, 1976, pp. 159-174. MetossI, D., "The Penal Question in Capital", en D. Platt y P. Takagi (eds.), Critical Criminology, Crime and Social Justice. Hong Kong, 1981, pp.187-204. Unos apuntes sobre la teoria del conflicto en CHAPMAN, T., "Crime in Eighteenth-Century England: E.P. Thompson and the Conflict Theory of Crime", Criminal Justice History, I (1980), pp. 139156. 
En un libro publicado en 1907, el Padre Jerónimo Montes sintetizó diversos estudios de antiguos escritores españoles sobre las causas del delito. El objetivo final de aquel ensayo no consistía únicamente en observar lo que nuestros antecesores habían contemplado como agentes impulsores de la delincuencia, sino también y sobre todo neutralizar las ideas de la Escuela positivista de criminología que durante la segunda mitad del XIX se habían consolidado fuertemente en Europa, las cuales, al postular la existencia del delincuente nato, negaban en cierta forma la libertad humana. El padre Montes rechazaba incondicionalmente semejantes ideas, argumentando que había causas que llevaban al hombre a delinquir, unas ocasionales y otras que predisponían al crimen, pero que las causas no producian por sí solas el acto criminal, sino que SIEMPRE hacía falta voluntad para cometerio. De hecho, según este autor, una persona podía verse impelida a robar y sin embargo tomar la dirección contraria, lo que venía a afirmar la libertad para actuar de uno $u$ otro modo ${ }^{14}$.

Una diferencia destacable entre la idea decimonónica de delincuente nato, cuyos autores consideraban al hombre que delinquía como un ser excepcional, enfermo, nacido para el crimen, o arrastrado a él por una fuerza irremediable (atavismo), y el pensamiento de los teólogos moralistas, místicos y filósofos del siglo XVI, es que éstos estudiaron al ser humano y sometieron a examen los móviles y las causas impulsivas de la voluntad, pero refiriéndose al hombre en general, sin distinguirle del delincuente ${ }^{15}$.

14 Montes, J., Estudios de antiguos escritores españoles sobre los agentes del delito. Madrid, 1907. Algunos de los títulos objeto de análisis en esa obra son Miranda Villafañe, Diálogos de la Phantástica Philosofía (1582); Fray Diego de Estella, Tratado de la Vanidad del mundo; Acosta Africano, Tratado en contra y pro de la vida solitaria (1592); Pedro de Covarrubias, $R e$ medio de jugadores (1543); Luis Vives, De Anima et vita, De Subventiorle pauperum, De Concordia et discordia, Introducción a la sabiduria; Juan Huarte de San Juan, Examen de ingenios; Fray Antonio de Guevara, Menosprecio de corte y alabanza de aldea (1539); Juan Caramuel, Teología moralis fundamentalis; Fray Luis de Granada, Guia de pecadores; Tomás de Castro y Ávila, Antídoto y Remedio único de daños públicos (1649); Padre Andrés Mendo, Príncipe perfecto y ministros ajustados (1661); Antonio Pérez Ramírez, Armas contra la fortuna (1698).

15 La filosofía mística y la teología cristiana del siglo Xvı se plasma en las obras de Santa Teresa, San Juan de la Cruz, Fray Luis de León, Fray Luis de Granada y otros muchos autores. En ellas se estudian las causas que conducen al hombre del pecado al vicio, y del vicio al crimen, se analizan los afectos del alma, los móviles de la voluntad, los pliegues de la conciencia y los sentimientos del corazón humano. También se señalan al hombre los medios de evitar el vicio y alcanzar la virtud; se enseña asimismo al hombre a dominar las pasiones, causa principal del crimen. Un estudio sintético el del Padre MONTES, J., Los principios del derecho penal según los escritores españoles del siglo xvı. Madrid. 1903. 
Las ideas de aquellos autores, en su mayoría teólogos moralistas, reunidas y sintetizadas por el Padre Montes, no abordaron problemas jurídicos penales (delitos), como ya observara Tomás y Valiente, sino los factores que originaban el crimen en términos exclusivamente morales. Si bien es cierto que los juristas nunca fueron indiferentes a la ciencia de los moralistas. De hecho, la doctrina de éstos sobre la responsabilidad humana giraba sobre dos principios que resultaban fundamentales para el derecho penal: la responsabilidad moral, no distinta de la criminal salvo en su extensión y objeto ${ }^{16}$, y el grado de responsabilidad, que nacía - según ellos- del mayor o menor grado de malicia y la mayor o menor libertad del sujeto.

Los factores que para estos autores influyeron con mayor o menor intensidad en la voluntad de las personas fueron los temperamentos, las pasiones, los hábitos, edad y sexo, la cultura intelectual, la educación, la imitación, el sentimiento religioso, las ocasiones y el pauperismo. Para entender cómo influyen los temperamentos en la voluntad de las personas hay que adquirir primero unas nociones básicas del funcionamiento fisiológico del ser humano. De acuerdo con la ciencia de Galeno, en la formación de las personas había cuatro únicos elementos: fuego, tierra, agua y aire, a los cuales correspondian las cuatro primeras calidades: calor, frialdad, humedad y sequedad, relacionadas a su vez con los humores del cuerpo: sangre, cólera, flema y melancolia. De estos humores, mezclados en proporciones diversas, nació la teoría de los cuatro temperamentos fundamentales: sanguíneo, colérico, flemático y melancólico. Del predominio de uno u otro temperamento se hizo depender la complexión y condiciones de cada individuo, pero también el carácter, la moral, el ingenio, así como las demás cualidades espirituales del hombre. Según los moralistas, el colérico tenía mayor propensión a la ira, y en consecuencia, a los delitos de sangre. Los melancólicos, al parecer, eran avaros y ambiciosos, y ante el temor a que les faltase lo necesario, eran dados al hurto. Por el contrario, los colérico sanguíneos poseían grandes virtudes. Lo más tranquilizador de esta forma de entender la fisiología en relación con el comportamiento humano es que los temperamentos cambian con la edad, generalmente a mejor ${ }^{17}$.

i6 La responsabilidad moral se extiende a todos los actos humanos, mientras que la criminal sólo a los delitos.

17 Montes, Estudios, pp. 200 y ss. 
Las pasiones, entendían los teólogos, eran necesarias a la naturaleza, y de ellas comenzaban y derivaban todos los actos humanos, buenos y malos. En su Guía de Pecadores, Fray Luis de Granada manifestaba que la pasión era «la más baja parte de nuestra ánima» y por consiguiente, la que más nos hacía semejantes a las bestias, las cuales se rigen únicamente por esos apetitos y afectos. Sin las pasiones, los moralistas no concebian el delito. Para ellos, la relación causal entre determinadas pasiones y el crimen era bien explicita: una ofensa provocaba ira y odio, y acababa incluso en asesinato; la codicia llevaba inexorablemente al delito contra la propiedad. Además, todos estaban de acuerdo en que resultaba muy difícil dominarlas y no dejarse llevar por ellas, asi como en que todas venian del amor del hombre a sí mismo. Según la filosofía aristotélica, muy seguida por nuestros ascetas, las pasiones tenían su raíz en el apetito sensitivo, y eran movimientos fuertes del mismo, cuyo origen fisiológico se atribuía a la sangre. Por eso, cuando una persona permanecía impasible ante una ofensa, se decía que no tenía sangre en las venas ${ }^{18}$.

Los moralistas escribieron también sobre la necesidad de la educación y su influencia en la costumbre. Como factor o causa del crimen, estos autores se formularon la siguiente cuestión: ¿es el hombre, por su naturaleza e instinto, inclinado al bien o inclinado al mal? Aquéllos que pensaban lo segundo, veían en la educación el único medio de dirigir al hombre por el camino de la virtud. Luis Vives, en su Introducción a la Sabiduría, manifestó que «... de ninguna cosa nace mayor riesgo a los hijos de los pobres, que de la vil, inmunda, incivil y tosca educación" ${ }^{19}$.

"La ocasión hace al ladrón» se decía ya en aquella época, y muchos autores vieron en las ocasiones una causa esencial del crimen, si bien otros manifestaron que era necesaria cierta predisposición para cometer delitos, pues en iguales circunstancias unos hombres delinquian y otros no. Fray Antonio de Guevara, Obispo de Mondoñedo, dice al respecto: «El malo y el vicioso son los que andan a buscar oportunidad para ser malos, que la virtud y el virtuoso a do quiera hallan lugar para ser buenos... para hombre bueno no hay oficio malo, para hombre malo no hay oficio bueno» ${ }^{20}$. Pero, ¿cuáles eran esas

18 Montes, Estudios, pp. 212-224

Montes, Estudios, p. 278.

20 Fray Antonio de Guevara, Menosprecio de Corte y alabanza de aldea. 1539 (Cap. II) Cfr., MCNTES, Estudios, pp. 162. 
ocasiones, dónde y cuándo se presentaban? Existían multitud de ellas, pero las más frecuentes se concentraban en la ociosidad, el juego y la vida urbana, especialmente de la corte.

Los tratadistas vieron en la ociosidad la madre de todos los vicios, particularmente si a ella se unía la pobreza, porque - argumentabanla necesidad de sustento para vivir y la repugnancia del trabajo honesto para conseguirle, obligaban al holgazán a delinquir. La condena de la ociosidad se hacía tanto más enérgica cuando ésta se practicaba en las grandes urbes, pues constataban que en ellas las ocasiones para delinquir se multiplicaban. Luis Vives calificó a las ciudades populosas como "verdaderas cloacas donde desaguan las inmundicias del Orbe entero, porque la maldad y el crimen no son consecuencia de la necesidad y la pobreza, sino de las riquezas y los placeres" ${ }^{21}$.

El juego propiciaba ocasiones innumerables, tanto para los delitos de sangre como contra la propiedad. Para Pedro de Covarrubias era claro que los jugadores eran ladrones, y creyó descubrirlo al dar la vuelta a la palabra Tahúr, que daba como resultado Hurta. Pero Las Partidas ya advertían de que los "tahúres e vellacos, usando la tahurería, por fuerza conviene que sean ladrones e ommes de mala vida". El párrafo de Castillo de Bovadilla resulta acaso más clarificador de lo que significaba el juego como causa de crímenes y maldades: “El juego es padre de la ociosidad, maestro de la pereza, instrumento de la avaricia, fragua de los fraudes, disipador de la hacienda y del tiempo, olvido de la familia, ocasión de ruidos y pendencias, de blasfemias y corrupción de costumbres, mancha de la dignidad, ignominia insigne, congoja de espíritu y fatiga continua» ${ }^{22}$.

La pobreza también fue vista por los intelectuales del momento como una causa mayor de la delincuencia. Aunque más que en la pobreza, pensaron en la desigualdad económica como el factor que enojaba el ánimo del pobre y le dirigía a la desesperación y al crimen, muy especialmente cuando la riqueza y el lujo se exhibian sin pudor ante el dolor de la miseria. En el siglo XVI se reconocía perfectamente la desigualdad «en los bienes de fortuna» como el origen de muchos delitos. Fox Morcillo (De regni regisque institutione) citaba entre las

21 Vives, L., De Concordia et Discordia. Libro III. Cfr., Montes, Estudios, pp. 323 y ss.

22 Castillo de Bobadilla, J., Política para corregidores y señores de Vasallos. Madrid, 1597, Libro II. Capítulo XIII. 
causas de las perturbaciones sociales ala desigualdad que resultaba de ser unos opulentos y otros extremadamente necesitados pobres... desigualdad que origina odios y contiendas". Pero fue Luis Vives tal vez quien con mayor contundencia descalificó el lujo y defendió al menesteroso. Suyo es el siguiente párrafo: “... los débiles y pobres, estrechados de la necesidad, fácilmente se entregan al hurto, tienen envidia a los ricos, se indignan e irritan porque a éstos les sobra para mantener bufones, perros, mancebos, mulas, caballos y otros animales, faltándoles a ellos qué dar a sus pequeños hijos hambrientos, y porque abusan soberbia e insolentemente de las riquezas que les han quitado e ellos, y a otros semejantes" ${ }^{23}$.

Otro de los aspectos que más destacaron nuestros tratadistas como agente del crimen fue la impunidad de los delitos. La justicia en la época moderna era considerada como fundamento del edificio social, alma de los estados y razón última de la autoridad. De resultas del alto concepto de justicia que tenían los intelectuales, éstos veían en la impunidad de los delitos la ruina de la sociedad, y uno de las causas principales de la delincuencia. Cerdán de Tallada, autor que contaba con muchos años de experiencia en asuntos penales, consignaba como factor crucial del delito las probabilidades con que contaba el delincuente para burlar la acción de los tribunales. Por eso postulaban sin ambages el rigor de la pena y la recta administración de la justicia. Claro que este mismo argumento se utilizaba también para confirmar el rigor de la pena como única solución para mantener a raya a los malhechores y defender a la sociedad.

\section{EL CRIMEN Y SU HISTORIOGRAFIA}

Explicaciones existen, como hemos tenido ocasión de comprobar, tal vez tantas como formas delictivas, por eso muchos historiadores han creído necesario detenerse más en la noción de delito y estudiar cómo ésta ha ido transformándose a lo largo del tiempo, adaptándose - como señaló Vic Gatrell- a lo que en cada momento legisladores, jueces y policias percibieron, "a través de los filtros de sus propios prejuicios sociales, intereses y asunciones", como actos que se salían

23 VIves, L., De Subventione. Libro II. Cfr., MONTES, Estudios. pp. 325 y ss. 
o quedaban fuera del derecho. Lo cierto es que al no haber delito sin una ley que lo defina ni un castigo que lo sancione, ha sido imprescindible examinar también la estructura y funcionamiento del aparato represor, así como los procedimientos legales con que el derecho penal y procesal se dotaban para acercarse más todavía a las causas de la delincuencia. De resultas del análisis de estos últimos aspectos han derivado nociones esenciales para comprender las pautas de comportamiento de hombres y mujeres "sin historia", así como determinados aspectos de la mentalidad de aquellas otras personas que, en el ejercicio del poder, construían el derecho y hacían funcionar los tribunales de justicia.

En las últimas décadas los historiadores se han preocupado en primer lugar de intentar construir las pautas de criminalidad y represión registradas en los distintos ámbitos europeos desde la Edad Media, y en segundo de dotarlas con una explicación coherente, que contemplara las peculiaridades de cada caso pero también los paralelismos que existiesen entre ellos. A partir de 1960 un amplio grupo de historiadores especialistas en el crimen y la justicia penal, guiados intelectualmente por Durkheim, encontró que con el derrumbe de las instituciones de la familia y la comunidad en la Europa moderna, y el advenimiento de la sociedad de masas, el crimen aumentó dramáticamente. Dentro de ese marco, algunos especialistas franceses -inspirados por Michael Foucault y basados en complejos análisis estadísticos- constataron el declive de los delitos violentos de forma paralela al incremento de los que atentaban contra la propiedad, instaurando así la conocida tesis de la violence au vol ${ }^{24}$.

Recientemente, sin embargo, reputados especialistas en la materia han tratado de desmontar esta tesis de la modernización, porque según sus análisis parciales no se sujeta a verificación empirica. Éstos han basado su rechazo en que la criminalidad ni aumentó en las sociedades modernas - capitalistas-, ni se concentró en las ciudades, y en que - además - el delito contra la propiedad no creció en

24 Véanse los artículos de Annales de Normandie entre 1962 y 1972 . También ZEHR, H., Crime and the development of Modern Society, patterns of criminality in nineteenth century Germany and France. London, 1976. THOME, H., "Modernization and Crime. What is the Explanation? ", IAHCCJ Bulletin, 20 (1995), pp. 31-48. CHaunu, P., Marginalité, Déviance, Pauvreté en France, xIV-xix Siècles. Caen, 1981. Foucault, M., Vigilar y Castigar. El Nacimiento de la Prisión. Madrid, 1990, 7." ed. 
tándem con el declive del violento. Por añadidura, casi todos ellos sostienen que la delincuencia registrada en la época moderna tan sólo informa al historiador de la actividad de los tribunales de justicia y de cómo era percibido el fenómeno por los poderes públicos, pero no sobre el comportamiento delictivo real en la sociedad. Bajo estas premisas únicamente se han atrevido a afirmar que la violencia criminal disminuyó desde la Edad Media hasta 1950, y que ello fue debido al control social ejercido por el estado, lo cual les ha llevado a hablar de una tesis de la civilización del crimen, cuyo padre intelectual no es otro que Norbert Elias ${ }^{25}$.

El interés por la historia de la delincuencia en España ha sido hasta ahora muy escaso, y lo poco que sabemos proviene en su mayor parte de los historiadores del derecho, que han introducido brillantes estudios sobre las figuras jurídico-penales más relevantes, como el delito, sus diferentes tipos, las penas, el indulto, el proceso penal, la tortura, los tribunales o la propia doctrina ${ }^{26}$; asi como de aquellos otros historiadores que se preocuparon del bandolerismo o de instituciones represivas como las hermandades ${ }^{27}$.

$\mathrm{Si}$ bien es cierto que los progresos que se vienen registrando actualmente en esta ciencia en España son ejemplares, tanto por la cantidad de estudios publicados como por la calidad de algunos de ellos, a pesar de que el atraso con respecto a otros paises europeos es todavia muy considerable ${ }^{28}$. Sobre el crimen y las instituciones encargadas de la justicia penal en Castilla, Valencia y Aragón contamos hoy con notables aportaciones, entre las que destacan los trabajos de Pablo

25 JONSON \& MONKKONEN (eds.), The Civilization of Crime: Violence in Town and Country since The Middle Ages. Chicago, 1996. JoHnson, E.A., Urbanization and Crime. Germany 1871-1914. Cambridge, 1995.

26 Escasez salpicada de notables excepciones, como son los estudios de Francisco Tomás y Valiente, Paz Alonso Romero, Bartolomé Clavero, Enrique Gacto, José Luis Bermejo Cabrero, y otros historiadores anteriores y más preocupados por la Edad Media como Orlandis, Rafael Gibert y otros.

27 Estudios como los de ZugAstI, J., El bandolerismo. Estudio social y memorias históricas, diez volúmenes. Madrid, 1876-1880; REGLÁ, Joan, El bandolerisme catalá del Barroc. Barcelona, 1962, 2. ${ }^{a}$ ed. Puyol Alonso, J., Las Hermandades de Castilla y León. Madrid, 1913. SUAREZ FERNANDEZ, L., "Evolución Histórica de las Hermandades castellanas", Cuadernos de Historia de España, XVI (1951), pp. 5-78.

28 Como se desprende bien a las claras del artículo de Clara Álvarez Alonso "Tendencias en la investigación del Derecho Penal Histórico. Los casos de Gran Bretaña, Francia e Italia como excusa", en Tomás y Valiente, Clavero y Otros, Sexo barroco y otras transgresiones premodernas. Madrid, 1990, pp. 197-213. 
Pérez García, José Luis de las Heras Santos, Palop Ramos o Tomás Mantecón, aunque existen otras muchas no menos relevantes ${ }^{29}$.

En el ámbito de la penalidad, tanto desde el punto de vista de los castigos aplicados a los reos, como del relativo a su legislación y práctica, también disponemos de un interesante elenco de publicaciones,

29 Domínguez Ortiz, A., “Delitos y suplicios en la Sevilla imperial», Crisis y decadencia en la España de los Austrias. Barcelona, 1969, pp. 11-72. Colas Latorre, G. y Salas Ausens, V.A., "Delincuencia y represión en Aragón durante el siglo XV|», Estudios del Departamento de Historia Moderna, 1976, pp. 79-146. Herrera Puga, P., Sociedad y delincuencia en el siglo de Oro. Granada, 1976. PÉrez Estévez, M.R., «Delincuencia en la España del siglo xVIII: los presidiarios de Marina", Cuadernos de Investigación Histórica, III (1979), pp. 259273. Perry, M.E., Crime and Society in Early Modern Seville. New England University, 1980. CRuz VAlEnCIANO, J., "Aspectos de la delincuencia en el siglo XVIIl. Las bandas de falsificadores de moneda", Cuadernos de Historia Moderna y Contemporánea, 7 (1986), pp. 33-64. SerRa I BARCELó, J., "Delinqüencia a Mallorca en el segle XVII (1613-19)", Bolletin Societat Arqueológica Lulliana, 43 (1987), pp. 105-146. MARTínez Soto, C., La delincuencia en Madrid. Siglo xvil. Memoria de licenciatura, Universidad Autónoma de Madrid, 1987. Aponte Marín, A., "Apuntes sobre la delincuencia en Jaén en la primera mitad del siglo XVII", Chrónica Nova, 15 (1987), pp. 9-26. HERNÁNDEZ SÁNCHEZ, F., "La corte envidiable: delincuencia y represión en el Madrid de Carlos IIl», en Equipo Madrid, Carlos III, Madrid y la llustración. Contradicciones de un proyecto reformista. Madrid, 1988. pp. 331-353. QUINTANA TORET, F.J., “De los delitos y las penas. La criminalidad en Málaga y su tierra durante los Siglos de Oro", STUDIS, 15 (1989), pp. 245-270. ALMAZÁN, I., «El recurso a la fuerza. Formas de violencia en el Vallés occidental durante el siglo XVI", Historia Social, 6 (1990), pp. 89-104. PÉrEz Garcia, P., La Comparsa de Ios Malhechores. Valencia 1479-1518. Valencia, 1990. WEISSER, M., Crime and Subsistence: the peasant of the "Tierra" of Toledo 1550-1700. Michigan, 1990. SÁNCHEZ BENITO J.M., "Criminalidad en la época de los Reyes Católicos. Delincuentes perseguidos por la Hermandad", Estudios de Historia Medieval. Homenaje a Luis Suárez Fernández. Valladolid, 1991, pp. 411-424. Heras Santos, J.L., La Justicia Penal de los Austrias en la Corona de Castilla. Salamanca, 1991. Sánchez Gómez, R.I., Delincuencia y seguridad en el Madrid de Carlos II. Tesis doctoral. Universidad Complutense. 1992. IBARS, T., La Delinqüència a la Lleida del Barroc. Lleida, 1994. PALOP RAMOS, J.M., "Notas sobre la criminalidad en Canarias durante el siglo XVIII», Homenaje a Antonio de Bethencourt Massieu. Las Palmas de Gran canaria, 1995, vol. III, pp. 19-28, "Delitos y penas en la España del siglo XV|lı, ESTUDIS, 22 (1996), pp. 65103, “Notas sobre la criminalidad en Galicia a finales del siglo xvili», Monografias y Fuentes, 20 - Conflictos y represiones en el Antiguo Régimen- (2000), pp. 181-208. MaNTEcón, T., "Meaning and social context of crime in preindustrial times: rural society in the North of Spain, 17th and 18th centuries", Crime, History \& Society, 1 (1998), pp. 49-73. Del mismo autor "Criminal and royal pardon in $18^{\text {th }}$ century Spain", Cahiers de l'Institut d'Anthropologie Juridique, 3 (1999), pp. 477-506, «Did Interpersonal violence decline in the Spanish Old Regime?", Memoria y Civilización, 2 (1999), pp. 117-140, «El poder de la violencia en el Norte de España: la Cantabria rural en la época moderna», I Encuentro de Historia de Cantabria. Santander, 1999, II, pp. 785-813. MENDOZA GARRIDO, J.M., Delincuencia y Represión en la Castilla Bajomedieval. Granada, 1999. AllozA, A., "El orden público en la Corte de Felipe II», J. Martinez Milín (Dir.), Felipe I/ (1527-1598) Europa y la Monarquia Católica. Madrid, 1998, pp. 29-51; "La economía criminal de los desheredados. Estudio comparativo de Londres, Madrid, París y Amsterdam en el siglo XVIII y comienzos del XIX", Revista Internacional de Sociología, 23 (1999), pp. 173-205. Alloza, A., Lopez García, J.M. y de Pablo Gafas, J.L., “Prevention 
registradas casi todas ellas durante las tres últimas décadas ${ }^{30}$. Y si hemos de destacar algunas, éstas son las de Ruth Pike, Ángel Rodriguez Sánchez, Pedro Trinidad y José Luis de las Heras Santos.

El estudio de las instituciones judiciales y policiales, acaso por tratarse de una temática integrada en aquella historia institucional dominante hasta 1970, ha gozado de mayor interés por parte de los historiadores. Pero no hay que sobrevalorar el potencial de este oasis en tan amplio desierto, porque un buen número de estudios tradicionales sobre instituciones judiciales y policiales, al abordar el objeto sin sujeto, alumbraron conclusiones que hoy no resistirian un asalto, si bien es cierto que han servido como base para nuevas investigaciones. Entre las más recientes e interesantes destacan las realizadas por José Luis de Pablo Gafas, pablo Pérez García y, aunque inédita todavía, la de Gómez Vozmediano sobre las Hermandades de Castilla la Macha ${ }^{31}$.

Resulta necesario, para finalizar, mencionar una vez más los trabajos procedentes de la "escuela de Salamanca" de historia del derecho,

and Repression. Food supply and public order in Early Modern Madrid", Revue des etudes de l'École française de Rome (MEFRIM), 112 (2000-2), pp. 615-644. MADRAZO, S., Estado débil y ladrones poderosos en la España del siglo xvil. Historia de un peculado en el reinado de Felipe $V$. Madrid, 2000.

30 Thompson, I.A.A. "A Map of Crime in Sixteenth Century Spain". Economic History Review, XXI, 2 (1968), pp. 244-267. Perez Estevez, M.R. El problema de los vagos en la España del siglo Xvili. Madrid, 1976. Trinidad, P. "La reforma de las cárceles en el siglo xix: las cárceles de Madrid", Estudios de Historia Social, 22-23 (1982), pp. 69-187; La defensa de la sociedad. Cárcel y delincuencia en España (siglos xvil-xix). Madrid, 1991. Heras Santos, J.L. "indultos concedidos por la Cámara de Castilla en tiempos de los Austrias", Studia Histórica, I, 3 (1983), pp. 115-141; del mismo autor "Los galeotes de los Austrias. La penalidad al servicio de la Armada». Historia Social, 6 (1990), pp. 127-140. PIKE, R. Penal Servitude in Early Modern Spain. Wisconsin, 1983; “Penal Practices in Early Modern Spain", Criminal Justice History, 5 (1984), pp. 45-55, “Capital punishment in Eighteenth-Century Spain», Histoire Sociale-Social History, XVIII, 36 (1985), pp. 375-386. Alvar EzQuerRA, A. “Algunas noticias sobre la vida diaria en la Cárcel de Corte de Madrid: la Visita de 1588-1589". Anales del Instituto de Estudios Madrileños, XXIII (1986), pp. 309-332. PALop Ramos, J.M. "La condena a presidio en Melilla. Aproximación a la criminalidad valencia del Setecientos». STUDIS, 15 (1989), pp. 271-288. Rodríguez SÁnchez, A. "La soga y el fuego. La pena de muerte en la España de los siglos XVi y XVII’. Cuadernos de Historia Moderna, 15 (1994), pp. 13-39. MARTiNez GARCIA, A. "Levas honradas y levas de maleantes: los trabajadores forzosos en un arsenai del antiguo régimen". Obradoiro de historia moderna, 8 (1999), pp. 231-260. CatALÁ SAnz, J. y Pérez Garcia, P. "La Pena Capital en la Valencia del Quinientos". Monografías y Fuentes, 20 - Conflictos y represiones en el Antiguo Régimen- (2000), pp. 21-112.

31 SUÁREZ Fernández, L., «Evolución Histórica de las Hermandades Castellanas", Cuadernos de Historia de España, 16 (1951), pp. 5-78. Dominguez Ortiz, A., "La galera o cárcel de mujeres de Madrid a comienzos del siglo xvill', Anales del Instituto de Estudios Madrileños, 
porque han estimulado notablemente el interés de los historiadores por esta temática, y sobre todo porque han resultado ser determinantes en el avance de la historia del crimen y la justicia penal en la España Moderna. Destacar a Tomás y Valiente y a Paz. Alonso Romero no es ningún mérito de quien esto escribe, sino un tributo merecido de toda la comunidad de historiadores de la delincuencia y su castigo ${ }^{32}$.

IX (1973), pp. 277-286. TOMÁs Y VALIENTE, F., «Las cárceles y el sistema penitenciario bajo los borbones", Historia 16 (1978), pp. 69-88. FIESTAS LOZA, A., "Las cárceles de mujeres", Historia 16 (1978), pp. 89-100. Cuesta PAScuAL, P., "Los alcaldes de barrio en el Madrid de Carlos III y Carlos IV", Anales del Instituto de Estudios Madrileños, XIX (1982), pp. 363-390. PÉREZ Baltasar, M.D., Mujeres Marginadas. Las Casas de Recogidas de Madrid. Madrid, 1984. MaRtinez Ruiz, E., La seguridad pública en el Madrid de la llustración. Madrid, 1988. Kagan, R., Pleitos y pleiteantes en Castilla, 1500-1700. Salamanca, 1991. Pérez Garcia, P., El Justicia Criminal de Valencia (1479-1707). Una magistratura urbana valenciana ante la consolidación del absolutismo. Valencia, 1991. Del mismo autor "Conflicto y represión: la justicia penal ante la Germania de Valencia (1519-1523)», ESTUDIS, 22 (1996), pp. 141-198. RIsco, A., "Espacio y control social: La Superintendencia General de Policía para Madrid y su rastro (17821808)", Madrazo, S. y Pinto, V. (eds.), Madrid en la época moderna: espacio, sociedad y cultura. Madrid, 1991, pp. 97-127. Villalba Pérez, E., La administración de la justicia penal en Castilla y en la Corte a comienzos del siglo xvil. Madrid, 1993. Gómez Vozmediano, F. y Martinez Rulz, E., "La Jurisdicción de la Hermandad", en MARTinez, E. y De Pazzis, M. (eds.), Instituciones de la España Moderna, Vol. I, "Las Jurisdicciones". Madrid, 1996, pp. 229-263. De Pablo Gafas, J.L., Justicia, Gobierno y Policia en la Corte de Madrid: la Sala de Alcaldes de Casa y Corte (1583-1834). Tesis Doctoral, Universidad Autónoma de Madrid, 2000.

32 Alonso Romero, M.P., El proceso penal en Castilla, siglos (xIII-xVIII). Salamanca, 1982. De la misma autora, "Aproximación al estudio de las penas pecuniarias en Castilla (siglos xillXVIII)", Anuario de Historia del Derecho Español, 45 (1985), pp. 9-94, y “Las Cortes y la Administración de la Justicia", en Las Cortes de Castilla y León en la Edad Moderna. Valladolid, 1989, pp. 501-564. Tomás y VALIENTE, F., El derecho penal de la Monarquía absoluta (siglos XVI, XVII XVIII). Madrid, 1969. Del mismo autor La tortura en España. 2. ${ }^{2}$ Ed., Barcelona, 1994, y con ClAVERO y ESPANHA y Otros autores, Sexo barroco $y$ otras transgresiones premodernas. Madrid, 1990. 